Journal of Business and Management Studies (JBMS)

ISSN: 2709-0876

DOI: $10.32996 / \mathrm{jbms}$

Journal Homepage: www.al-kindipublisher.com/index.php/jbms

\title{
The Influence of Leadership Behaviour on Organizational Culture Among the Academic Deans of State Universities and Colleges (SUCs) in Panay Island, Philippines
}

\author{
Ronel B. Amorin, PhD \\ Faculty, West Visayas State University-Calinog Campus, Iloilo, Philippines \\ $\square$ Corresponding Author: Ronel B. Amorin, PhD, E-mail: ronel.amorin@wvsu.edu.ph
}

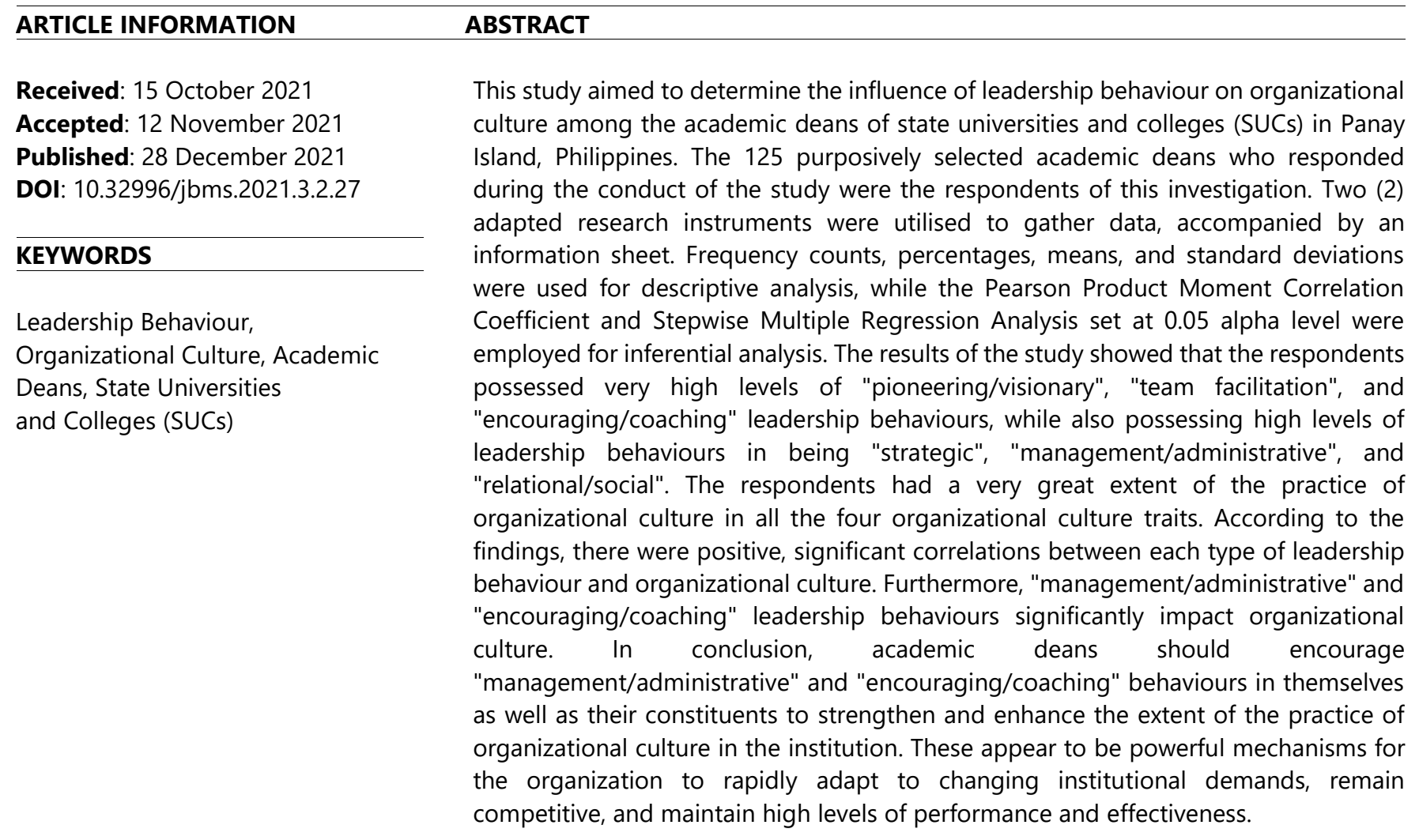

\section{Introduction}

In the Philippines, the higher education system has changed dramatically in recent years. The key milestone is for state universities and colleges (SUCS) to conform to the regulations imposed by the Commission on Higher Education (CHED) and other accrediting agencies in the country to achieve its educational goals and objectives. As a result, higher education institutions (HEls) put a great emphasis on appointing qualified, dynamic, competent, and highly trained academic deans who are directly responsible and accountable for academic and scholarly activities as well as institutional outcomes in general. These academic leaders are required to exhibit appropriate leadership characteristics in establishing their own culture, which has a favourable impact on organizational outcomes. Thus, the effectiveness of faculty members in carrying out their academic, scholarly, and developmental activities may also be dependent on the academic dean's leadership behaviour.

According to Leithwood, Anderson, and Wahlsttom (2004), leadership is a key step in providing educational change and organizational growth. The academic leaders' task is to implement a vision-driven change of direction (Bryman, 1992), which has the evident capacity to preserve and develop an organization's culture. Academic leaders must be adaptable enough to manage

Copyright: (C) 2021 the Author(s). This article is an open access article distributed under the terms and conditions of the Creative Commons Attribution (CC-BY) 4.0 license (https://creativecommons.org/licenses/by/4.0/). Published by Al-Kindi Centre for Research and Development, London, United Kingdom. 
diverse teams by bringing together people of various personalities, ages, and cultures around a common goal. They confront obstacles in the real world while they perform tasks and activities since they are accountable for the outcomes of the academic organizations they serve. Their actions can establish and, at the very least, influence organizational culture (Denison, 1990; Hofstede et al., 1990; Schein, 1997).

Leaders develop culture by expressing their personal values and expectations of an organization. Leaders of new organizations have a significant effect on an organization's culture (Schein, 1992). Organizational culture is essential within an organization since it comprises people and is where human interaction is the custom. However, it should be understood that academic leaders' activities must be consistent with the organization's culture. What works for one organization may not work for another. Different organizations may have distinctive kinds of cultures. According to Sorensen (2002), organizational culture is a shared understanding among members of an organization about norms, practices, and procedures that promote goal alignment and facilitate consistency in purposes and practices. The alignment between stated principles and actual behaviours improves organizational performance.

In this light, the author would like to determine the level of leadership behaviour and extent of organizational culture practised by the academic deans in SUCs. Further, this study aims to find out the impact of leadership behaviours on organizational culture.

\section{Literature Review}

\subsection{Leadership Behaviour}

According to Yukl (2002), leadership is frequently a notion with many varied connotations, and there is no single, widely accepted definition. If we look at the several definitions of leadership, we can see that there is some uniformity on an essential aspect of what leadership, at least, is about, including "influence," "group," and "goal" (Bryman, 1992). Burns (1978) conducted one of the most significant studies on leadership behaviour; his research impacted many other researchers and established the foundation of leadership behaviour studies. Burns (1978) in Makaske (2015) defines leadership as: "Leaders inducing followers to act for certain goals that represent the values and the motivations - the wants and needs, the aspirations and expectations —of both leaders and followers."

Leadership is characterized as an influential interaction between leaders and followers who anticipate meaningful changes and outcomes that reflect their common goals (Daft, 2005). Northhouse (2012) added that it is a mechanism through which a person inspires a group of others to attain a common purpose. All of these characteristics are reflected in the definition of De Jong (2007), who stressed that leadership is the act of impacting others in order to lead, organize, and enable interactions and relationships in a team or organization towards that specific result.

There are several approaches to leadership, and various leadership characteristics have been described in preceding leadership studies. The focus of theorists used to be on the traits and actions of leaders, but this has shifted to the role of followers and the nature of leadership in recent years (Bryman, 1992). As studies continue to explore what contributes to leadership success and failure, various dimensions or aspects of leadership behaviour have been established and utilized over time. However, as far as this study is concerned, the researcher utilized the six (6) leadership behaviours that academic deans should possess according to the United Nations Office for the Coordination of Humanitarian Affairs (UN-OCHA) (2010), in Grabato (2016):

Pioneering/visionary. It describes a leader who demonstrates and conveys potential outcomes; has contagious passion and enthusiasm; is a proactive person and pushes the limits of what is possible; is strongest in the initial phases of a project or objective conceptualization, and is unaware of personal risks.

Strategic. A leader who disintegrates visions and large goals into distinct sequential steps, has understanding and emphasis on working out how to realize the goals, is excellent at formulating strategies and convincing others to embrace the plan, is capable of creating possible alternatives and evaluating the advantages and disadvantages of each, anticipates the future and plans for possible scenarios.

Management/Administrative. A leader who is great at managing work activities and individuals, has thorough strategies and problem-solving skills, can coordinate, arrange, follow-through, and accomplish projects on schedule; he is the "implementer"who makes things happen.

Team Facilitation. This is the actions of a leader who is a competitive player; who encourages functioning together along with different individuals, institutions, or agencies; who likes to work with others interdependently and believes them implicitly; who perceives himself/herself as representing the overarching team goals; who is proficient at enabling both the function and operation components of teams; who mediates conflict; and who is ready to manage different viewpoints. 
Relational/Social. This is the "people's person"; appreciates being with others and considers their experience or existence fascinating; appears to care about the mental and physical wellbeing of other individuals; finds that others share information about him/her in their emotions, interactions, confusion, self-esteem issues, etc.; and looks for opportunities to enjoy or interact socially as a group.

Encouraging/coaching. A transformational leader is an educator, trainer, team manager, and supporter; is great at convincing and inspiring others; naturally and effortlessly recognizes other people's capacity, gifts, emotions, and intentions; asserts just the correct thing at the perfect time; understands when to challenge, when to assist, when to mentor, and when to give space.

\subsection{Organizational Culture}

According to Robbins and Coulter (2005), organisational culture is described as the common beliefs, attitudes, or perceptions held by individuals within an organization or organizational unit. Organizational culture has the capacity to influence the thoughts and actions of its members because it embodies the values, beliefs, and behavioural standards that individuals in an organization have used to bring clarity to the experiences they have shared (Scott-Findlay \& Estabrooks, 2006). It is a set of common fundamental assumptions that an organization understands because it faces external adjustment and internal integration difficulties, and it has been shown to be accurate enough to be imparted to team members as the appropriate way of understanding, thinking, and feeling about those challenges (Schein, 2004).

Lee (2008) described organizational culture as a double-edged sword that generates distinctions between one organization and others, enables individuality for its members, enhances the stability of the social system, minimizes uncertainty, and serves as a control mechanism that directs and forms employees' attitudes and actions. A culture, on the other hand, can become a liability when it becomes too deeply embedded in the employees' standards, principles, and belief systems and withstands change, becoming a barrier to innovation, distinctiveness, and other modifications required for the organization to adapt in today's rapidly changing, competitive business world. One of the organizational level elements impacting individuals' dedication and moral conduct in an organization, their perception of team membership, their productivity, identity, and persistence is organizational culture (Khan \& Rasli, 2015; Kreitner \& Kinicki, 2004). In other words, workplace culture also substantially impacts individuals' attitudes, behaviours, and perceptions in attaining organizational aims and objectives.

Whatever is accomplished, how it will be performed, and who will be participating in doing something reflects the culture of a higher education institution. It is concerned with both instrumental and symbolic decisions, behaviours, and communication. It includes stories, special language, standards, organizational philosophy, and mindsets that evolve through organizational and individual actions (Tierney, 1988, in Coman \& Bonciu, 2016). Academic leaders and administrators in universities sometimes have only an instinctive understanding of the cultural situations and variables that impact their everyday decision-making. They are only minimally aware of cultural values, standards, representations, ideas, and practices, and they tend to perceive workplace culture only when disputes are likely to emerge and unfavourable interactions appear in a number of ways. As a consequence, instead of quiet contemplation and consensual transformation, individuals find themselves dealing with organizational culture in a crisis-like environment (Tierney, 1988, in Coman \& Bonciu, 2016). In universities, organizational culture plays a significant role in the overall success of organizational change and is an essential component of the responsive planning process (Franlinger, 2007; Lincoln, 2010). The university culture is multifaceted since the attitudes and behaviours of administrators, senior officials, faculty and staff, campus community members, competitors, and society all work together to determine the organisation's performance.

Organizational cultures may be evaluated along with various aspects, yielding theoretically distinct but basically comparable models and theories. The following covers the literature and supporting studies about the cultural characteristics of the Denison Organizational Culture Model in this study. According to Denison (2000), organizational culture refers to the basic beliefs, philosophies, and conceptions that serve as the foundation for an organizational hierarchy, including management strategies and activities that embody and support such fundamental principles. Denison (1990) outlines four fundamental aspects of organizational culture that may be expressed into hypotheses emphasizing cultural elements, which include the following: (1) involvement, (2) consistency, (3) adaptability, and (4) mission. 


\begin{tabular}{|l|l|}
\hline ADAPTABILITY & MISSION \\
\hline INVOLVEMENT & CONSISTENCY \\
\hline \multicolumn{2}{|l}{} \\
\hline Change and Flexibility & Stability and Direction \\
\hline
\end{tabular}

Figure 1: Denison's Model of Culture and Effectiveness Source: Adapted from Denison (1990)

According to the involvement hypothesis, organizational performance is dependent on the level of engagement and commitment of an individual involved. A high degree of engagement and involvement fosters a sense of accountability and control. This ownership leads to a stronger commitment to the organization and a higher ability to work in ambiguous situations. Consequently, there is stronger employee commitment to the organization, which reduces the need for formal systems of control and leads to improved performance. According to Denison et al. (2006), involvement is measured using three indices: empowerment, where individuals have the power, creativity, and capability to control their individual activities; participation, where individuals have the power, creativity, and capability to control their individual activities; and participation, where individuals have the power, creativity, and capability to control their individual activities. This develops a sense of authority and accountability for the organization. Next is the team orientation, which puts an emphasis on functioning together toward a mutual purpose for which all team members feel jointly accountable. To complete tasks, the organization relies on teamwork. Then, capability development, in which the organization consistently spends on the skills development of the workforce in order to compete effectively and satisfy continuing business demands.

The consistency hypothesis emphasized that communication is a more credible mechanism for conveying information in consistent cultures because there is a strong consensus on the meaning of words, actions, and other symbols. Furthermore, Denison (2000) contends that a shared standpoint, similar views, and collective ideals among the organization's members would improve internal collaboration and provide purpose and a feeling of identity among its members. Consistent organizations cultivate a mentality and establish organizational mechanisms that support an internal system of governance based on consensus. This form of consistency is a potent source of organizational integration and stability. According to Denison et al. (2006), this model is assessed using three indices, including core values, in which members of the organization embrace a set of values that provide individuality and definitely expected behaviours. Next, there's the agreement, which happens when an organization's workforce can agree on crucial problems. This encompasses the capacity to resolve conflicts when they arise as well as the underlying degree of agreement. Then, the coordination and integration, where different teams and units of the organization may collaborate to attain organizational goals and organizational divisions, don't get in the way of getting things done.

According to the adaptability hypothesis, a culture that allows an organization to adjust to changing needs and circumstances promotes effectiveness. Adaptability enables the organization to perceive and adapt to its surrounding environment as well as its internal constituency. It is necessary to be able to reconfigure behaviours and systems in response to either internal or external influences (Denison, 2000). Organizations with high flexibility often achieve profitability and have a competitive edge (Denison \& Mishra, 2005). Adaptability is assessed in the model by the ability to produce change; when an organization is capable of creating adaptable procedures to meet changing needs, it is able to read the working environment, react promptly to innovations, and anticipate prospective developments. It is followed by customer focus, demonstrating how much the organization is driven by the desire to serve its customers. The organization comprehends and responds to its clients and foresees their increasing demands. Finally, organizational learning is the process through which an organization absorbs, processes, and analyzes information from its environment to discover opportunities. These opportunities are utilized to foster creativity, knowledge acquisition, and skill development (Denison et al., 2006).

In a mission hypothesis, a culture that provides a mutual meaning of an organization's functions and operations is consistently correlated with investing their efforts in the organization's well-being. It also facilitates acknowledging the priorities and objectives, allowing the organization to select relevant plans of action. A sense of mission enables the organization to change present behaviour by conceptualizing an intended future outcome. Internalizing and identifying with an organization's mission promotes both short-term and long-term organizational commitment (Denison, 2000). Three indicators are used to assess the mission. First, the strategic direction and intent, where the explicit strategic objectives transmit the organization's mission and make it apparent how others can participate and "leave their mark" in the industry (Denison et al., 2006). According to Baker (2002), the planning process and identification are essential for sustaining the organizational culture. Next, the goals and objectives, wherein a defined set of goals and objectives may be connected to the purpose, goal, and plan and present a reasonable direction in individual activities (Denison et al., 2006). According to Benko (2001), for an organization to operate effectively, it must be able to design a 
future strategy and have a clear idea of where it is headed and how it intends to get there. Finally, the vision, which represents the organization's common vision for a better future, reflects fundamental values and attracts the minds and hearts of its members while imparting support and guidance (Denison et al., 2006).

All academic deans need to understand organizational culture because it impacts how their organizations adapt to continuously evolving demands. An organization's culture is strongly influenced by its previous accomplishments and lessons learned about adjusting and succeeding in any specified timeframe. As the work environment develops, leaders must continually expect the required adjustments and actively evaluate the interaction between the expectations of the environment and the capabilities of the organization.

\subsection{Leadership Behaviour and Organizational Culture}

Leaders influence organizational culture, and organizational culture influences leadership behaviours. Leadership and organizational culture are interrelated and mutually beneficial (Sharma \& Sharma, 2010). Despite the notion that leaders influence organizational culture, cultural practices impact the leadership behaviours of educational leaders. In this context, organizational culture represents an organization's fundamental beliefs and value system (Sharma \& Sharma, 2010). Culture refers to a collection of shared beliefs, attitudes, ideas, and standards, some explicit and some not (Brown, 2004). Therefore, academic leaders become both architects and products of organizational culture.

According to Yang (2007), culture is understood and shared by members on a social level; it sets the underlying norms for organizational behaviour. A basic principle of an organization originates with its leadership, which develops into a style of leadership. Subordinates will be inspired by these principles and their leaders' behaviour; hence, both sides' behaviour should become more consistent. A strong organizational culture develops when strong, unified behaviour, values, and beliefs are created. Leaders must recognize the importance of their role in sustaining an organization's culture. This, in turn, would promote appropriate behaviour across members of the organization, eliminating disputes and establishing a positive job atmosphere (KaneUrrabazo, 2006).

Assessing the management and leadership styles in the organization is important when reforming characteristics of culture since leaders are there to influence and drive people during societal change (Harvey \& Brown, 1996). When leaders are evaluated, their leadership styles should be examined, and agreements should be made among all parties involved on where adjustments are needed. Evaluation methods of management competency models would assist in determining development needs such as competencies and understanding, identifying one's own commitment and motivation to a cultural shift, and examining leadership traits, views, expectations, and leadership behaviours for a workplace diversity (Pretorius, 2004). This assessment gives insight into where individual leaders could focus in order to function effectively during cultural reforms.

The leadership hierarchy in universities and colleges establishes parameters. In other words, regardless of other cultural dimensions inside the institution, the faculty is expected to respect the mandates of the academic deans. Bennis and Nanus (1985) and Sergiovanni (2000) added that effective school leaders might analyze and establish a culture that meets the values and expectations of the school and community. According to Deal and Peterson (1999), comprehensive and inclusive leadership generates the best and healthiest cultures.

The cross-sectional study conducted by Tsai (2011) about the relationship between organizational culture, leadership behaviour, and job satisfaction revealed that organizational cultures were considerably and positively associated with leadership behaviour and job satisfaction, and leadership behaviour was highly and significantly correlated with job satisfaction. Casida and Pinto-Zipp (2008) also investigated nurses in establishing the relationship between different leadership styles and organizational cultures and found a correlation between leadership and organizational culture, consistent with the findings of Tsai (2011). Using regression analysis, Tsai (2011) discovered that leadership behaviour impacts organizational culture. Klein, Wallis, and Cooke (2013) investigated the impact of leadership styles on organizational culture and organizational effectiveness. The findings mainly confirm the predictions that organizational success is related to the cultural type and that cultural norms are related to leadership styles. According to the findings, managers' and supervisors' leadership qualities are crucial in forming and reinforcing cultural norms. Furthermore, cultural norms appear to have a favourable effect on organizational effectiveness.

In his study, Taormina (2008) discovered a fascinating pattern of relationships after linking leadership behaviours, organizational socialization, and organizational culture. As a consequence of the regression study, it was revealed that both leadership and socialization explained considerable variance in all cultures. Rahman and Jantan (2020) studied how leadership behaviour influences organizational commitment, organizational culture, and work satisfaction at a Malaysian public university and found a 
positive and exceptionally high correlation between leadership behaviour and organizational culture. Moreover, the study about organizational culture as influenced by leadership styles in the case of private businesses in Kosovo by Lokaj and Sadrija (2020) found a significant positive relationship between leadership style and organizational culture by analyzing components such as stimulation, responsibilities, and motivation.

In this investigation, the researcher focused on the six (6) leadership behaviours that academic deans should possess, according to the United Nations Office for the Coordination of Humanitarian Affairs (UN-OCHA) (2010). The leadership behaviours possessed by the academic deans were emphasised in this context. They are expected to have a significant impact on the culture of the SUCS in Panay Island.

\section{Methodology}

A descriptive-correlational research design was used in the study. The study's respondents were all the one hundred twenty-five (125) academic deans managing undergraduate and graduate programs of state universities and colleges (SUCs) in Panay Island, Philippines. The study employed the purposive sampling approach in determining the number of respondents. According to Foxcroft and Roodt (2002), Purposive sampling is sampling done with a clear objective. Purposive sampling is a type of nonrandom sampling in which respondents are intentionally sought out or utilized while gathering exploratory data from a nonstandard population. It can be highly beneficial in cases when a targeted sample is required immediately, and proportionality sampling is not the major issue.

The researcher solicited permission to use survey instruments. Adapted data-gathering instruments consisting of two (2) questionnaires accompanied by information sheets about the demographic and work-related profiles of the participants were utilized in the study. After being pilot-tested, all instruments were found reliable to ascertain their administrability in the actual setting.

The Team Roles Questionnaire (Emergency Field Coordination Training, United Nations Office for the Coordination of Humanitarian Affairs (OCHA), 2010) was also used in the study of Grabato (2016). This data-gathering instrument was utilized to obtain data on the academic deans' leadership behaviours. The instrument was reliable because of the obtained reliability coefficient of .93. It is in a 5-point Likert scale format and is composed of 30 items that describe six (6) leadership behaviours exhibited by academic deans: (1) pioneering/visionary, (2) strategic, (3) management/administrative, (4) team facilitation, (5) relational/social, and (6) encouraging/coaching.

The Organizational Culture Survey by Daniel R. Denison (2011) was also used in the study of Gloria (2017). This data-gathering instrument had a reliability coefficient of97, indicating that it was reliable. This data-gathering instrument point is in a 5-point Likert scale format and contains 36 items in four categories, namely: (a) member involvement - 9 items; (b) consistency - 9 items; (c) adaptability -9 items; and (d) mission -9 items.

The data was gathered prior to the COVID-19 pandemic; thus, the researcher personally distributed and administered the reproduced data-gathering instruments to the respondents. The data-gathering instrument contained directions for completion. For ethical considerations, the researcher emphasized the confidentiality and privacy of the data and that the gathered data would only be for academic and research purposes.

The data gathered from the investigation was subjected to the following statistical tools for analysis using Statistical Packages for Social Science (SPSS) version 21 software. For descriptive data analysis, frequency counts, percentages, means, and standard deviations were used, while Pearson Product Moment Correlation Coefficient and Stepwise Multiple Regression Analysis with a 0.05 alpha level were used as inferential statistics. The result was significant if the $p$-value was less than.05.

Data in Table 1 reveal that of the 125 academic deans who participated in the study, 36 (28.80\%) were affiliated with state colleges, while 89 (71.20\%) were affiliated with state universities. As to campus assignments, 68 (54.40\%) were assigned to the main campus, while $57(45.00 \%)$ were assigned to the satellite campus. When grouped according to sex, $46(36.80 \%)$ were males, and $79(63.20 \%)$ were females participated in the study. In terms of highest educational attainment, 13 (10.40\%) were master's degree holders, 34 (27.20\%) were masters with doctorate units, and $78(62.40 \%)$ were doctorate degree holders. When grouped according to academic rank, 25 (20.00\%) were instructors I to III, 42 (33.30\%) were assistant professors I to IV, 46 (36.80\%) were associate professors I to $\mathrm{V}$ and $12(9.60 \%)$ were professors I to VI. As to teaching experience, a large majority of 60 (48.00\%) had 17 years, and below teaching experience, 31 (24.80\%) had 18 to 27 years in teaching, and 34 (27.20\%) had 28 years and above teaching experience. When grouped according to experience as academic head, a large majority of $74(59.20 \%)$ had been academic heads for 4 years and below, and 51 (40.80\%) had been academic heads for 5 years and above. In terms of size of faculty managed, a bulk number of $73(58.40 \%)$ managed 35, and below faculty, 26 (20.80\%) managed 36 to 60 faculty, 15 (12.00\%) managed 61 to 85 faculty, and 
11 (8.80\%) managed 86 and above faculty. As to school/college enrolment, 14 (11.20\%) of the academic heads belong to SUCs with 1,553 and above students, 24 (19.20\%) belong to SUCs with 796 - 1,552 students and 87 (69.60\%) belong to SUCs with 795 and below students.

Table 1. Respondents' Profile

\begin{tabular}{|c|c|c|}
\hline Category & Frequency & Percentage \\
\hline A. Entire Group & 125 & 100.00 \\
\hline \multicolumn{3}{|l|}{ B. School Affiliated } \\
\hline State University & 89 & 71.20 \\
\hline \multicolumn{3}{|l|}{ C. Campus } \\
\hline \multicolumn{3}{|l|}{ D. Sex } \\
\hline Male & 46 & 36.80 \\
\hline Female & 79 & 63.20 \\
\hline \multicolumn{3}{|l|}{ E. Highest Educational Attainment } \\
\hline Master's Degree & 13 & 10.40 \\
\hline Assistant Professor I to IV & 42 & 33.60 \\
\hline Associate Professor I to V & 46 & 36.80 \\
\hline Professor I to VI & 12 & 9.60 \\
\hline \multicolumn{3}{|l|}{ G. Teaching Experience } \\
\hline 28 years and above & 34 & 27.20 \\
\hline $18-27$ years & 31 & 24.80 \\
\hline 17 years and below & 60 & 48.00 \\
\hline \multicolumn{3}{|l|}{ H. Experience as Academic Dean } \\
\hline 5 years and above & 51 & 40.80 \\
\hline 4 years and below & 74 & 59.20 \\
\hline $796-1,552$ & 24 & 19.20 \\
\hline 795 and below & 87 & 69.60 \\
\hline
\end{tabular}

\section{Results and Discussion}

\subsection{Perception Level of Agreement on Six Leadership Behaviour}

Table 2 displays the mean scores and standard deviations of the respondents' degrees of agreement on six leadership behaviours. It showed that the mean scores for the six leadership behaviours ranged from 3.96 to 4.25. The highest perceived level of agreement was in encouraging and coaching $(M=4.25, S D=0.45)$. The next highest was team facilitation $(M=4.23, S D=0.52)$. This is followed by pioneering/visionary $(M=4.21, S D=0.54)$. Then, by strategic $(M=4.19, S D=0.49)$ and management/administrative $(\mathrm{M}=4.14, \mathrm{SD}=0.51)$. The lowest mean score was relational $/$ social $(\mathrm{M}=3.96, \mathrm{SD}=0.56)$.

The respondents have very high levels of leadership behaviours in terms of pioneering/visionary, team facilitation, and encouraging/coaching. These simply indicate that, as a transformational leaders, they are good at persuading and motivating others. They are team builders who facilitate working with different people or organizations and visualize and communicate future possibilities to attain organizational goals (OCHA, 2010, in Grabato, 2016). Effective leadership provides encouragement, and we 
expect the leader to be pleasant, conscientious, and morally driven and to provide a developmental direction for improvement (Leithwood et al., 2006).

Further, the respondents have high levels of leadership behaviours in strategic, management/administrative, and relational/ social dimensions. It appears that they have shown concern about the health and wellbeing of other people in the organization. Moreover, they have such an ability to manage tasks and their people. These leadership characteristics may contribute to the generation of strategic and relational organizational capital in a constructive and meaningful way (Akram et al., 2016). In order to meet operational objectives, education leaders must implement principles in order to protect and promote the ideals of democracy, personal rights, accountability, fairness, social justice, the environment, and diversity (National Policy Board for Education Administration, 2015).

Table 2: The Level of Leadership Behaviour

\begin{tabular}{llll}
\hline Leadership Behaviour & Mean & SD & Description \\
\hline Pioneering/Visionary & 4.21 & .54 & Very High \\
Strategic & 4.19 & .49 & High \\
Management/Administrative & 4.14 & .51 & High \\
Team Facilitation & 4.23 & .52 & Very High \\
Relational/Social & 3.96 & .56 & High \\
Encouraging/Coaching & 4.25 & .45 & Very High \\
\hline Overall & $\mathbf{4 . 1 6}$ & & High \\
\hline
\end{tabular}

Scale:

$\begin{array}{ll}\text { Mean } & \text { Description } \\ 4.21-5.00 & \text { Very High } \\ 3.41-4.20 & \text { High } \\ 2.61-3.40 & \text { Average } \\ 1.81-2.60 & \text { Low } \\ 1.00-1.80 & \text { Very Low }\end{array}$

\subsection{Extent of Practice of Organizational Culture}

Table 3 displays the four organisational culture traits' mean scores and standard deviation. As indicated in Table 3, the mean scores ranged from 4.21 to 4.40 . This shows that the greatest extent of an organizational culture trait practice was involvement ( $\mathrm{M}=4.40$, $S D=0.46)$. Next was the mission $(M=4.38, S D=0.50)$. Then, the adaptability $(M=4.29, S D=0.50)$ Lastly, the consistency $(M=$ $4.21, S D=0.58$ ). Based on Table 3, respondents had a very great extent of the practice of organizational culture in all four of the organizational culture traits.

The results imply that the respondents show a very high degree of involvement in work and activities in the organization that require their support and help. It thus appears that the academic heads are also very consistent in exercising their managerial practices and roles and tend to treat everyone equally. They are likewise adaptive to change and are innovative, creative, and willing to accept suggestions and input from other organisation members. According to Oakland (2001), an organisation's views, attitudes, norms, prevailing ideals, laws, and environment shape its culture. According to him, the success of an organization is determined by how well individuals conduct their tasks and work toward shared goals and priorities. The respondents' great extent of the practice of organizational culture is consistent with Werner and De Simone's (2009) claims that positive attitudes among organizational participants, especially academic heads, are beneficial for a better understanding of organizational events. With such knowledge, the academic deans know what is expected of them and the appropriate behaviour in the workplace.

Table 3. The Extent of Practice of Organizational Culture

\begin{tabular}{llll}
\hline Organizational Culture & Mean & SD & Description \\
\hline Involvement & 4.40 & .46 & Very High Extent \\
Consistency & 4.21 & .58 & Very High Extent \\
Adaptability & 4.29 & .50 & Very High Extent \\
Mission & 4.38 & .50 & Very High Extent \\
\hline Overall & $\mathbf{4 . 3 2}$ & & Very High Extent \\
\hline
\end{tabular}

Scale:

$\begin{array}{ll}\text { Mean } & \text { Description } \\ 4.21-5.00 & \text { Very High Extent } \\ 3.41-4.20 & \text { High Extent }\end{array}$



2.61-3.40
$1.81-2.60$
Moderate Extent
Low Extent
$1.00-1.80$
Very Low Extent

\subsection{Correlation Analysis between the Six Leadership Behaviours and Organizational Culture}

Based on De Vaus's (2002) interpretation of correlation coefficients, Table 4 displays the Pearson Product Moment Correlation Coefficient between the six leadership behaviours and organizational culture.

Table 4. Designation Strength of Association Based on Size of Correlation Coefficients

\begin{tabular}{lll}
\hline Strength of Association & Negative & Positive \\
\hline Low to moderate & -0.29 till -0.10 & 0.10 till 0.29 \\
Moderate to substantial & -0.49 till -0.30 & 0.30 till 0.49 \\
Substantial to very strong & -0.69 till -0.50 & 0.50 till 0.69 \\
Very strong & -0.89 till -0.70 & 0.70 till 0.89 \\
Near perfect & -0.99 till -0.90 & 0.90 till 0.99 \\
Perfect relationship & -1.00 & 1.00 \\
\hline
\end{tabular}

As shown in Table 5, the correlation results between the six leadership behaviours and the extent of the practice of organizational culture revealed a significant correlation $(p<0.001)$, ranging from substantial to very strong and positive strength of association. Specifically, organizational culture was significant, positive, and had a substantial to very strong correlation with pioneering/visionary behaviour $(r=0.635 ; p<0.001)$, strategic behaviour $(r=0.571 ; p<0.001)$, management/administrative behaviour $(r=0.675 ; p<0.001)$, team facilitation behaviour $(r=0.610 ; p<0.001)$, relational/social behaviour ( $r=0.557 ; p<0.001)$, and encouraging/coaching behaviour $(r=0.647 ; p<0.001)$. This means that, to a substantial or very strong extent, an increase in the six leadership behaviours is associated with an increase in the extent of the practice of organizational culture.

This was supported by Sharma and Sharma (2010), stating that leadership and organizational culture are interrelated and have a mutually beneficial connection. In other words, leaders can have an impact on organizational culture, and organizational culture can have an impact on leaders. A study conducted by Tsai (2011) confirmed that organizational cultures were significantly and positively associated with leadership behaviour and job satisfaction. Likewise, Rahman and Jantan's (2020) study also found a positive and exceptionally high correlation between leadership behaviour and organizational culture.

Table 5. Correlation Analysis between Each Type of Leadership Behaviour and Organizational Culture

\begin{tabular}{|c|c|c|c|c|c|c|}
\hline Variables & LB $^{1}$ & $\mathrm{LB}^{2}$ & LB $^{3}$ & LB $^{4}$ & LB $^{5}$ & LB $^{6}$ \\
\hline Organizational Culture & $.635^{\star \star *}$ & $.571^{\star \star \star}$ & $.675^{\star \star \star}$ & $.610^{* \star *}$ & $.557^{\star \star \star}$ & $.647^{* \star *}$ \\
\hline Pioneering/Visionary $\left(\mathrm{LB}^{1}\right)$ & 1.00 & $.758^{\star * \star}$ & $.785^{\star \star \star}$ & $.801^{* \star *}$ & $.786^{\star \star *}$ & $.785^{\star \star *}$ \\
\hline Strategic $\left(\mathrm{LB}^{2}\right)$ & & 1.00 & $.732^{\star \star *}$ & $.807^{\star \star *}$ & $.785^{\star \star \star}$ & $.733^{\star * *}$ \\
\hline Management/Administrative $\left(\mathrm{LB}^{3}\right)$ & & & 1.00 & $.762^{\star * *}$ & $.699 * * *$ & $.730 * * *$ \\
\hline Team Facilitation $\left(\mathrm{LB}^{4}\right)$ & & & & 1.00 & $.755^{\star \star \star}$ & $.779 * * *$ \\
\hline Relational Social $\left(\mathrm{LB}^{5}\right)$ & & & & & 1.00 & $.750 * * *$ \\
\hline Encouraging/ Coaching $\left(\mathrm{LB}^{6}\right)$ & & & & & & 1.00 \\
\hline
\end{tabular}

$* \star * p<0.001$

A stepwise regression analysis was done to determine the significant predictors of the extent of practice organizational culture. The six leadership behaviours were used as predictor variables in this study, whereas organizational culture was regarded as the dependent variable. The objective of calculating this regression equation was to explore leadership behaviours that significantly impact the extent of the practice of organizational culture.

\subsection{Regression Analysis between the Six Types of Leadership Behaviour and Organizational Culture}

Table 6 reveals that 2 of the 6 components of leadership behaviour predicted the extent of the practice of organizational culture significantly. Management/administrative and encouraging/coaching behaviours accounted for $50.6 \%$ of the variation in organizational culture, $F(2,122)=62.579, p=.000$. The magnitude of the standardized coefficient $(\beta)$ in this analysis directly reflects the relevance of these factors in relation to one another. Management/administrative behaviour $(\beta=0.434)$ was the most important predictor in this context, followed by encouragement/coaching $(\beta=0.330)$, in that order. 
Table 6. Regression Analysis of Leadership Behaviour and Organizational Culture

\begin{tabular}{lllll}
\hline Variables & B & $\boldsymbol{\beta}$ & t & p-values \\
\hline Constant & 1.263 & - & 4.458 & .000 \\
Management/Administrative $\left(\mathrm{LB}^{3}\right)$ & .392 & .434 & 4.670 & .000 \\
Encouraging/Coaching $\left(\mathrm{LB}^{6}\right)$ & .338 & .330 & 3.545 & .001 \\
$\mathrm{R}=0.712, \mathrm{R}^{2}=0.506, \mathrm{SEb}=0.327, \mathrm{~F}=62.579$ & & & &
\end{tabular}

Within the allowed range between 1.50 and 2.50, the Durbin-Watson statistic of 1.969 indicates the absence of serial correlations among residuals, which is a favourable sign for the model because it is error-independent. Values that fall outside of this range could be a troublesome issue. According to Field (2009), there is a definite cause for concern when obtained values are under 1 or more than 3 .

The multivariate linear regression model that follows depicts the relationship between the components of predictor variables and the dependent variable.

Unstandardized score: $\mathrm{OC}=1.263+0.392\left(\mathrm{LB}^{3}\right)+0.338\left(\mathrm{LB}^{6}\right)$

Standardized score: $\mathrm{OC}=0.434\left(\mathrm{LB}^{3}\right)+0.330\left(\mathrm{LB}^{6}\right)$

\section{Conclusion}

The academic deans have a very high level of leadership behaviour in terms of pioneering/visionary, team facilitation, and encouraging/coaching. It simply reveals that they are willing to take risks in being a leader and become proactive in all organizational endeavours. They also have this sense of responsibility to encourage different members of the organization to work well together. Furthermore, as leaders, they have a positive influence on their followers. Moreover, they have high-level leadership behaviour in terms of strategic, management/administrative, and relational/social dimensions. Being strategic indicates that they are good at planning and are effective "problem-solvers" in the institution. This also shows that they can be described as a good project or program implementers and know how to manage their constituents in performing their duties and responsibilities. Furthermore, they have shown warmth and kindness to the people in the organization.

The academic deans had a very great extent of the practice of organizational culture in all the four organizational culture traits. As a result, it appears that academic leaders are also relatively reliable in their organizational practices and responsibilities, and they tend to treat people equally. It seems that they really practice what they preach, and the members in different parts of the organization share a common perspective. It can also be inferred that they are incredibly adaptable, flexible, imaginative, dynamic, and responsive to ideas and involvement from other members of the organization. Academic deans in the organization understand what needs to be done for them to succeed in the long run and share a common mission and vision of what the organization will be like in the future.

There are significant correlations between the six leadership behaviours and the extent of the practice of organizational culture. This simply means that the behaviours manifested by the academic deans significantly influence their culture in the organization. This suggests that a healthy organizational culture is associated with the leader's healthy behaviour. As a result, these leadership practices can help to foster a positive workplace environment. Furthermore, if needed, these actions might play a significant role in transforming the organisation's culture.

Management/administrative and encouraging/coaching behaviours are significant predictors of the extent to which organizational culture is practised. It can be inferred that these leadership behaviours manifested by the academic deans significantly affect the organizational cultural practices. Being the "implementer" and "trainer" or "coach" as a leader will increase the extent of the practice of organizational culture. It can be said that these behaviours and actions can potentially create and shape a desirable and acceptable culture in the organization. These characteristics should be promoted in achieving organizational goals and objectives. These appear to be powerful mechanisms enabling the organization to adjust to fast-changing institutional requirements, maintain a competitive edge, and ensure outstanding results and performances.

Academic deans' leadership behaviour inside the institution may substantially impact the work environment. As a result, organizational culture is an important factor in determining whether an organization is a strong and productive workplace. It would benefit the organization if the leader and followers engaged more to achieve the organization's goals and objectives, which would contribute to its overall effectiveness. Thus, both leadership behaviour and organizational culture play vital roles in the organization because they can determine whether or not an organization succeeds. 
Funding: This research received no external funding.

Acknowledgements: The author would like to thank the different state universities and colleges (SUCs), both their main and satellite campuses, for providing all the data needed in this investigation. The author also extends his sincere gratitude to the university presidents, campus administrators, academic deans managing the undergraduate and graduate programs in seven (7) SUCs in Panay Island, Philippines.

Conflicts of Interest: The author declares no conflict of interest.

\section{References}

[1] Akram, T., Leib, S., Hussain, S.T., Haiderb, M.J , \& Akram, M.W. (2016). Does relational leadership generate organizational social capital? A case of exploring the effect of relational leadership on organizational social capital in China. Future Business Journal, 2(2), 116-126. https://www.sciencedirect.com/science/article/pii/S2314721016300123

[2] Anderson, J. R. \& Wahsttom, J. (2004). Situated learning and education. Educational Researcher, 25(4), 5-11.

[3] Baker, K. (2002). Organizational culture. www.findarticles.com/p/articles.html

[4] Benko, L. (2001). Getting the royal treatment. Modern Health Care, 39(1), $28-32$.

[5] Bennis, W. \& Nanus, B. (1985). Leaders: The strategies for taking charge. Simon \& Schuster.

[6] Brown, R. (2004). School culture and organization: Lessons from research and experience [A background paper for the Denver Commission on Secondary School Reform]. https://www.dpsk12.org/pdf/culture organization.pdf

[7] Bryman, A. (1992). Charisma and Leadership in Organization. Sage Publications.

[8] Casida, J \& Pinto-Zipp G. (2008). Leadership-organizational culture relationship in Nursing units of acute care hospitals. Nursing Economics, 26(1), 7-15.

[9] Coman, A. \&, Bonciu, C. (2016). Organizational culture in higher education: Learning from the best. European Journal of Social Sciences Education and Research. 135

[10] Daft L., (2005). The Leadership Experience (3rd ed.).

[11] De Jong, J. (2007). Individual innovation: The connection between leadership and employees' innovative work behaviour. PhD University of Twente, EIM: Zoetermeer.

[12] De Vaus, D. (2002). Analyzing social science data. Sage Publications Limited.

[13] Deal, T.E. \& Peterson, K. D. (1999). Shaping school culture: The heart of leadership. Jossey-Bass.

[14] Denison, D. (1990). Corporate culture and organizational effectiveness. John Wiley \& Sons.

[15] Denison, D. (2000). The International handbook of organizational culture and climate. John Wiley \& Sons.

[16] Denison, D., Jonovics, J., Young, J., \& Cho, H. (2006). Diagnosing organizational cultures: Validating a model and method. www.denisonculture.com

[17] Denison D.R. \& Mishra A.K. (2005). Toward a theory of organizational culture and effectiveness. Organization Science, 6(2). $204-223$.

[18] Field, A. (2009). Discovering statistics using SPSS (3rd ed.). Sage Publications.

[19] Foxcroft, C., \& Roodt, G. (2002). An introduction to psychological assessment in the South African context. Oxford University Press, Inc.

[20] Fralinger, B. (2007). Organizational culture at the university level: A study using the OCAl instrument. Journal of College Teaching \& Learning, 4(11), 85-98.

[21] Gloria, M. S, (2017). Technology, culture and productivity. Unpublished Doctor of Education Dissertation. West Visayas State University, Lambunao Campus, Lambunao, Iloilo.

[22] Grabato, L.P. (2016). Academic heads' leadership behaviour, psychological empowerment, professional development impact as related to organizational effectiveness: Inputs to leadership enhancement Plan. Unpublished Doctor of Philosophy Dissertation. West Visayas State University, La Paz, lloilo City.

[23] Harvey, D., \& Brown, D. (1996). An experiential approach to organizational development (5th ed). Prentice-Hall.

[24] Hofstede, G., Neuijen, B., Ohayv, D.D. \& Sanders, G. (1990). Measuring organizational cultures: A qualitative and quantitative study across twenty cases. Administrative science quarterly, 35(2), 286-316.

[25] Kane-Urrabazo, C. (2006). Management's role in shaping organizational culture. Journal of Nursing Management, 14, 188-194.

[26] Khan, M. M., \& Rasli, A. M. (2015). Relationship between organization culture, empowerment and conflict. International Journal of Economics and Financial Issues, 5.

[27] Klein, A., Wallis, J., \& Cooke, R. (2013). The impact of leadership styles on organizational culture and firm effectiveness: An empirical study. Journal of Management \& Organization, 19(3), 241-254. https://doi:10.1017/jmo.2013.34

[28] Kreitner, R., \& Kinicki, A. (2004). Organizational behaviour (6th ed.). McGraw-Hill.

[29] Lee, H.Y. (2008). The association between organizational culture and leadership behaviour and organizational commitment, job satisfaction and employee performance - A Malaysian perspective. https://www.semanticscholar.org/paper/The-association-between-organizationalculture-and-Lee/a598260a9acc262db57c7912e2ab8bc97ed756bc

[30] Leithwood, R. (2004). Impact of transformational leadership on empowerment: mediating role of social identity. International Journal of Leadership, 2(1), 34-42.

[31] Leithwood, K, Day, C, Sammons, P, Harris, A \& Hopkins, D, (2006). Seven strong claims about successful school leadership. Nottingham, National College for School Leadership. 
[32] Lincoln, S. (2010). From the individual to the world: how the competing values framework can help organizations improve global strategic performance. Emerging Leadership Journeys, 3 (1), 3-9. http://www.regent.edu/acad/global/publications/elj/vol3iss1/Lincoln ELV3I1 pp39.pdf

[33] Lokaj, A.S. \& Sadrija, T. L. (2020). Organizational culture influenced by leadership styles: the case of private businesses in Kosovo. Problems and Perspectives in Management, 18(3), 306-314. https://doi.org/10.21511/ppm.18(3).2020.25

[34] Makaske, I.C. (2015). The effect of leadership behaviour on work climate and team effectiveness. https://essay.utwente.nl/67485/1/Makaske BA faculty.pdf

[35] National Policy Board for Educational Administration (2015). Professional Standards for Educational Leaders. http://www.npbea.org/wpcontent/uploads/2017/06/Professional-Standards-for-Educational-Leaders2015.pdf

[36] Northouse, P. (2012). Leadership: Theory and Practice. Sage Publications.

[37] Pretorius, W. (2004). The impact of organizational culture on effectiveness. www.upetd.up.ac.za/thesis/available/etd3162004131828

[38] Rahman, M.R.Z. and Jantan, A.H (2020). Leadership behaviour influences organizational commitment, organizational culture and job satisfaction at public universities in Malaysia. Journal of International Business and Management, 3(2), 01-13.

[39] Robbins S.P, \& Coulter M. (2005). Management (8th ed.). Pearson Prentice Hall.

[40] Schein, E.H. (1992). Organizational culture and leadership (2nd ed.). Jossey-Bass.

[41] Schein, E. H. (1997). Organizational culture and leadership (2nd ed.). Jossey-Bass.

[42] Schein, E.H. (2004). Organizational Culture and Leadership (3rd ed.). Jossey-Bass.

[43] Sergiovanni, T.J. (2000), The life world of leadership: creating culture, community, and personal meaning in our schools. Jossey-Bass Publishers.

[44] Scott-Findlay, S, Estabrooks C. A. (2006). Mapping the organizational culture research in nursing. In: A literature review. Journal of Advanced Nursing, 56(5), 498-513.

[45] Sharma, S. K., \& Sharma, A. (2010). Examining the relationship between organizational culture and leadership styles. Journal of the Indian Academy of Applied Psychology, 36(1), 97-105

[46] Sorensen, J. B. (2002). The Strength of Corporate Culture and the Reliability of Firm Performance. Administrative Science Quarterly, 47(1), 70-91. https://doi.org/10.2307/3094891

[47] Taormina, R. J. (2008). Interrelating Leadership Behaviors, Organizational Socialization, and Organizational Culture. Leadership \& Organization Development Journal, 29, 85-102. https://doi.org/10.1108/01437730810845315

[48] Tsai Y. (2011). Relationship between organizational culture, leadership behaviour and job satisfaction. BMC health services research, 11, 98. https://doi.org/10.1186/1472-6963-11-98

[49] Werner, M. J., \& De Simone, L. R. (2009). Human Resource Development (5th ed.). Cengage Learning India Private Limited.

[50] Yang, J. (2007). Knowledge sharing: Investigating appropriate leadership roles and collaborative culture. Tourism Management, 28, 530-543.

[51] Yukl, G.A. (2002). Leadership in Organizations (5th ed.). Prentice-Hall. 